Research Article

\title{
Knowledge and practice on drug compliance among males with hypertension
}

\author{
Vanitha Durai*, Anitha Rani Muthuthandavan
}

Department of Community Medicine, Sri Ramachandra Medical College and Research Institute, Sri Ramachandra University, Porur, Chennai, Tamil Nadu, India

Received: 20 March 2016

Accepted: 26 April 2016

*Correspondence:

Dr. Vanitha Durai,

E-mail: dvanitha2015@gmail.com

Copyright: () the author(s), publisher and licensee Medip Academy. This is an open-access article distributed under the terms of the Creative Commons Attribution Non-Commercial License, which permits unrestricted non-commercial use, distribution, and reproduction in any medium, provided the original work is properly cited.

\begin{abstract}
Background: Treat to goal was the theme of world hypertension day in 2006 which ensured patients compliance and hypertensive control. In hypertensive care drug compliance is a prime factor. Antihypertensive drugs are highly adhered by $50 \%$ of hypertensive. Poor blood pressure control result in many complications, leading to huge economic burden. Objectives of the study to find the level of knowledge and current practice on drug compliance with antihypertensive drugs among males with hypertension.

Methods: A cross sectional study was conducted in November 2013, using an interview schedule among 100 males with hypertension in age group of 30-59 years who attended hypertension clinic of medicine Outpatient Department in a Medical College Hospital, Chennai, Tamil Nadu.

Result: Out of 100 hypertensive, 54\% had education less than high school level, nearly half of them were from rural population, doing unskilled work and $64 \%$ had hypertension for less than 5 years. Among participants $63 \%$ were aware that medications should be continued throughout life and $81 \%$ were aware that drugs should not be stopped even if blood pressure is under control. Drug compliance rate as prescribed was 52\% during last 2 weeks. Noncompliance rate at more than 2 times were $22 \%$ and less than that were $26 \%$.Common reasons for noncompliance were busy schedule (50\%), forgetfulness (33.3\%) during consuming alcohol (9\%) and others.

Conclusion: Drug compliance was very poor among males with hypertension, could be addressed by health care providers.
\end{abstract}

Key words: Drug compliance, Hypertension, Knowledge, Practice

\section{INTRODUCTION}

Hypertension is the most significant risk factor for death and disease burden. WHO reports that hypertension has caused about 9.4 million deaths and $7.0 \%$ disability adjusted life years (DALYs) globally in 2010. The global burden of hypertension will increase by $60 \%$ to a total of 1.56 billion hypertensive adults by 2025 . Majority of this rise can be attributed to increase in the number of hypertensive adults from economically developing regions. In 2011, The Global Status on Non-
Communicable Diseases Report mentioned that in India there were more than 2.5 million deaths from cardiovascular disease in 2008. Coronary heart disease caused two-thirds of death and stroke caused the remaining death.

Goal for hypertension treatment is to decrease the associated morbidity and mortality. Complications of uncontrolled hypertension are cerebrovascular, cardiovascular renal and retinal diseases. This leads to poor quality of life and affects health economics as it 
causes permanent disability or death which increases the burden to family, community and nation. Cardiovascular complications are angina, myocardial infarction, left ventricular hypertrophy, coronary arterial disease and heart failure. Cerebrovascular problems are hypertensive encephalopathy, transient ischemic attacks, ischemic strokes, cerebral infarcts and hemorrhages. Hypertension causes kidney failure, peripheral arterial disease, retinopathies, papilledema and blindness. In a Tanzanian study history of hypertension was found among twothirds of patients who died from stroke and so to avoid stroke it was proposed to include control of high blood pressure, thus drug compliance become vital.

In a study antihypertensive drug compliance was found to reduce the risk of stroke and coronary heart disease by $34 \%$ and $21 \%$. Studies have also revealed that medication therapy improves life expectancy and quality of life. About $92 \%$ of compliant patients had controlled blood pressure in Eastern Sudan in contrast with $18 \%$ of noncompliant patients. Improved control can lead to avoidance of 3 lakhs of the 15 lakhs annual deaths from cardiovascular diseases in India. Drug compliance is a cost saving intervention.

WHO in 2003 mentioned that noncompliance to medical treatment is a major public health concern in patients with hypertension. Noncompliance to antihypertensive drugs or lifestyle modifications can be associated with uncontrolled hypertension and it causes complications. Treat to Goal was the theme of World Hypertension day in 2006 which ensured patients compliance and control of hypertension. Poor compliance decreases optimum clinical benefits and reduces the overall effectiveness of health systems and treatment. ${ }^{11}$ Interventions aimed at improving drug compliance would provide a significant positive return on investment through secondary prevention of adverse health outcomes. ${ }^{11}$

Noncompliance to medication comprises of four factors. Medication factors comprising of frequency of doses, number of drugs, adverse effects, unpleasant taste or smell of pills and compatibility to daily activities or lifestyle which are presently overcome through prescription of combination drugs, reducing the frequency of the daily doses and by changing the drug in case of adverse effects, manufacturing smaller size pills and avoid unpleasant taste and smell. Healthcare system factors comprising of cost of drug, usage of many pharmacies/physicians, long waiting time and unhappiness with their healthcare provider which are presently overcome by making drugs available at free of cost, easy accessibility of healthcare facility and healthcare providers providing pleasing services. Disease factors comprising of a few existing symptoms and chronic conditions which are overcome through health education about modifiable lifestyle practices for hypertension, drug compliance and complications of hypertension. Patient centered factors are also a factor for noncompliance. ${ }^{15}$ This paper considers patient-centered factors as valuable risk factor for noncompliance.

Patient's knowledge regarding drug compliance in hypertension and its complications as well as their practice are some of the key factors in achieving compliance to medication and control of blood pressure . Most of the previous study revealed that males are more noncompliant than females. Hence this paper discusses about drug compliance among males alone. In an outpatient care settings, feasible, reliable, and valid measure of drug compliance with less cost and time factors is standardized questionnaire. The aim of this study was to assess the drug compliance, factors associated with it and the reasons for noncompliance among hypertensive patients.

\section{METHODS}

This was a cross sectional study conducted among the hypertensive males (30-59 years) who were attending Hypertension clinic of Medicine Department in a Medical College Hospital, Chennai, Tamil Nadu for at least 1 year, willing to participate and have given the informed consent. On an average about 160 hypertensive patients were attending for outpatient care at Hypertensive clinic daily. Among them nearly 80 hypertensive were males, in which 10-12 males were from the age group of 30-59 years. Data collection was done for a period of 10 days in November 2013 using an interview schedule. All hypertensive males in the age group of 30-59 years attending hypertensive clinic in Medicine department during data collection period were included as sample in this study. Hypertensive males who were hospitalized during last 30 days or with serious illness were excluded. In a latest study published in India among the hypertensives, the compliance rate was $50 \%$ with $5 \%$ significant level, the limit of accuracy as $20 \%$ of anticipated prevalence, the minimum sample size required was 96 and the same was rounded as 100. This study was approved by Institutional Research Ethical committee, Sri Ramachandra University, Chennai. Data analysis was done using statistical package for social sciences (SPSS) version 16 software.

\section{RESULT}

Socio demographic factors-The study result of 100 males with hypertension in the age group of 30-59 years who were attending a tertiary care hospital in Chennai are presented here. Mean age of participants was 51 years $(\mathrm{SD}=6.9)$ ranging $32-59$ years. Mean duration of hypertension was 4.3 years $(\mathrm{SD}=3.9)$ ranging $1-20$ years. Among the participants $66 \%$ were from the age group of 50 or more years, $49 \%$ were from middle and low socioeconomic status, $64 \%$ were hypertensives for less than 5 years duration and $75 \%$ had diabetes mellitus as comorbidity. Nearly half of participants were from rural area $(51 \%)$, with education less than high school level $(54 \%)$ and $49 \%$ were unskilled workers. 
Table 1: Description about knowledge on drug compliance $(\mathbf{n}=\mathbf{1 0 0})$.

\begin{tabular}{|lll|}
\hline Knowledge about & Frequency & $\%$ \\
\hline $\begin{array}{l}\text { Medications not to be stopped } \\
\text { even if their body condition } \\
\text { was good. }\end{array}$ & 81 & 81 \\
\hline $\begin{array}{l}\text { Medications not to be stopped } \\
\text { even if their blood pressure } \\
\text { was under control }\end{array}$ & 81 & 81 \\
\hline $\begin{array}{l}\text { Medications not to be stopped } \\
\text { till end of life }\end{array}$ & 63 & 63 \\
\hline $\begin{array}{l}\text { Antihypertensive drugs not to } \\
\text { be doubled if they missed } \\
\text { previous dose }\end{array}$ & 99 & 99 \\
\hline $\begin{array}{l}\text { At least one complication } \\
\text { regarding noncompliance }\end{array}$ & 72 & 72 \\
\hline $\begin{array}{l}\text { Any four factors pertaining to } \\
\text { drug-compliant }\end{array}$ & 72 & 72 \\
\hline
\end{tabular}

*Knowledge about any four among the above five variables.

Table 2: Reasons for noncompliance among 100 hypertensives.

\begin{tabular}{|lll|}
\hline Reasons & Frequency & Percentage \\
\hline Too busy & 24 & 50 \\
\hline Forgetfulness & 16 & 33.30 \\
\hline During alcohol consumption & 4 & 8.30 \\
\hline Do not believe in treatment & 2 & 4.20 \\
\hline Financial problems & 1 & 2.10 \\
\hline Side effects & 1 & 2.10 \\
\hline
\end{tabular}

\section{Knowledge}

About $81 \%$ of the hypertensives knew that antihypertensive drugs should not be stopped even if their health condition was good, $81 \%$ knew that antihypertensive drugs should not be stopped even if their blood pressure was under control and $63 \%$ knew that they had to take antihypertensive drugs till their life. Majority of the participants (99\%) knew that they should not double the drugs even if they missed previous drugs and $72 \%$ knew that if the drug was not taken regularly could develop cardiac problem. In this study $72 \%$ of the hypertensives had good knowledge about any four factors (four among the above five factors) pertaining to drugcompliance. (Table 1). Renal, cerebral and ocular complications were known by $60 \%, 55 \%$, and $28 \%$ of study participants respectively. Minimum of 3 complications of hypertension regarding noncompliance of hypertensive drugs were known by $70 \%$ of the hypertensives.

\section{Practice}

About 26 (26\%) participants missed drugs for 2 or lesser times, $13(13 \%)$ missed 3 to 5 times, $6(6 \%)$ missed 6 to 10 times and $3(3 \%)$ missed more than 10 times. Totally $48(48 \%)$ hypertensives missed medication at least once in the past 2 weeks (Figure 1). Main reason for noncompliance was busy schedule of life $24(50 \%)$, forgetfulness $16(33.3 \%)$, alcohol consumption 4 (8.3\%) where alcoholics deliberately skipped drugs during alcohol consumption. Two participants $(4.2 \%)$ were diagnosed as hypertensives during treatment for other illness and as they had no symptoms of hypertension, they did not believe in medical care and took the drugs irregularly. Though drugs were available free of cost in this hospital $1(2.1 \%)$ participant missed drugs due to financial problem in his family and $1(2.1 \%)$ avoided drugs due to fear of side effects, since he believed that antihypertensive drug intake can cause kidney problem (Table 2). Totally $52 \%$ of the hypertensives took antihypertensive drugs regularly during the past 2 weeks as prescribed.

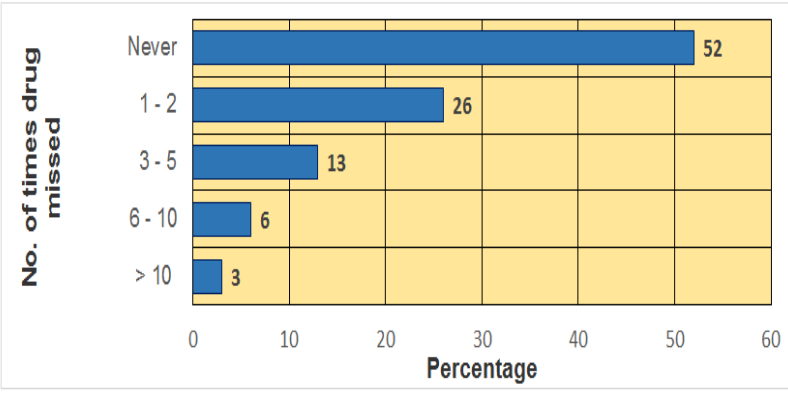

Figure 1: Pattern of drug compliance during last 2 weeks $(n=100)$.

Compliance rate according to various factors (Table 3).

Among the compliant higher proportion (58\%)of the hypertensives who had knowledge that they should not stop antihypertensive drugs even when the blood pressure is under control were 3.9 times more drug compliant when compared to the hypertensives who had no knowledge about it $(26.3 \%),(\mathrm{p}=0.128)$. Compliance rate was more among the hypertensives who had awareness (54\%) that they should not stop antihypertensive drugs till the end of their life when compared to the hypertensives without awareness about it (48.7\%). Larger proportion of hypertensives who had knowledge about cardiac complications $(61.1 \%)$ were found to be 3.9 times more drug compliant when compared to the hypertensives who had no knowledge about it (28.6\%), $(\mathrm{p}=0.0035)$.

Greater proportion of hypertensives who had knowledge about minimum of 3 complications of hypertension regarding noncompliance $(60 \%)$ were found to be 3 times more drug compliant than their counterpart who had no knowledge about it $(33.3 \%),(\mathrm{p}=0.0145)$. The participants who had good knowledge $(59.7 \%)$ about any four factors pertaining to drug compliance were 3.1 times more compliant with antihypertensive drugs than who had poor knowledge about it $(32.1 \%),(\mathrm{p}=0.0132)$. 
Noncompliance rate at more than 2times according to various factors among noncompliant $(n=48)$. Among the noncompliant who missed medications at more than 2 times, from the age group of 50 or more years $(58.63 \%)$, missed medications by 3.9 times, when compared to the participants from the age group of less than 50 years $(26.32 \%),(\mathrm{p}=0.0280)$.

Table 3: Compliance rate according to various factors among hypertensives $(n=100)$.

\begin{tabular}{|c|c|c|c|c|c|c|}
\hline \multirow[t]{2}{*}{ Various factors } & & & \multicolumn{2}{|c|}{ Pattern of drug compliance } & \multirow{2}{*}{$\begin{array}{l}\text { Odds } \\
\text { ratio }\end{array}$} & \multirow[t]{2}{*}{ p value } \\
\hline & & & $\begin{array}{l}\text { Compliant } \\
(\%)\end{array}$ & $\begin{array}{l}\text { Non-Compliant } \\
(\%)\end{array}$ & & \\
\hline \multirow[t]{6}{*}{ demographic factors } & \multirow[t]{2}{*}{ Age Group } & $\geq 50$ years & $37(56.1)$ & $29(43.9)$ & \multirow[t]{2}{*}{1.616} & \multirow[t]{2}{*}{0.2584} \\
\hline & & $<50$ years & $15(44.1)$ & $19(55.9)$ & & \\
\hline & \multirow{2}{*}{$\begin{array}{l}\text { Socio economic } \\
\text { status }\end{array}$} & Low & $27(55.1)$ & $22(44.9)$ & \multirow[t]{2}{*}{1.267} & \multirow[t]{2}{*}{0.5428} \\
\hline & & High & $25(49)$ & $26(51)$ & & \\
\hline & \multirow[t]{2}{*}{ Residence } & Rural & $29(56.9)$ & $22(43.1)$ & \multirow[t]{2}{*}{1.490} & \multirow[t]{2}{*}{0.3207} \\
\hline & & Urban & $23(46.9)$ & $26(53.1)$ & & \\
\hline \multirow[t]{4}{*}{ Illness factors } & \multirow{2}{*}{$\begin{array}{l}\text { Hypertension } \\
\text { duration }\end{array}$} & $\geq 5$ years & $20(55.6)$ & $16(44.4)$ & \multirow[t]{2}{*}{1.250} & \multirow[t]{2}{*}{0.5935} \\
\hline & & $<5$ years & $32(50)$ & $32(50)$ & & \\
\hline & \multirow[t]{2}{*}{ Co Morbidity } & Present & $44(55.7)$ & $35(44.3)$ & \multirow[t]{2}{*}{2.043} & \multirow[t]{2}{*}{0.1514} \\
\hline & & Absent & $8(38.1)$ & $13(61.9)$ & & \\
\hline \multirow{10}{*}{$\begin{array}{l}\text { Knowledge factors-Aware } \\
\text { of }\end{array}$} & \multirow{2}{*}{$\begin{array}{l}\text { Not to stop drugs } \\
\text { even if BP is under } \\
\text { control }\end{array}$} & Aware & $47(58)$ & $34(42)$ & \multirow[t]{2}{*}{3.871} & \multirow[t]{2}{*}{0.0128} \\
\hline & & Not aware & $5(26.3)$ & $14(73.7)$ & & \\
\hline & \multirow{2}{*}{$\begin{array}{l}\text { Taking drugs till } \\
\text { the end of the life }\end{array}$} & Aware & $34(54)$ & $29(46)$ & \multirow[t]{2}{*}{1.238} & \multirow[t]{2}{*}{0.607} \\
\hline & & Not aware & $18(48.7)$ & $19(51.3)$ & & \\
\hline & \multirow{2}{*}{$\begin{array}{l}\text { Cardiac } \\
\text { complication } \\
\text { regarding } \\
\text { noncompliance }\end{array}$} & Aware & $44(61.1)$ & $28(38.9)$ & \multirow[t]{2}{*}{3.929} & \multirow[t]{2}{*}{0.0035} \\
\hline & & Not aware & $8(28.6)$ & $20(71.4)$ & & \\
\hline & \multirow{2}{*}{$\begin{array}{l}\text { Any three } \\
\text { complications } \\
\text { regarding } \\
\text { noncompliance }\end{array}$} & Aware & $42(60)$ & $28(40)$ & \multirow[t]{2}{*}{3.000} & \multirow[t]{2}{*}{0.0145} \\
\hline & & Not aware & $10(33.3)$ & $20(66.7)$ & & \\
\hline & $\begin{array}{l}\text { Any four factors } \\
\text { pertaining to drug } \\
\text { compliance }\end{array}$ & Good & $43(59.7)$ & $29(40.3)$ & 3.130 & 0.0132 \\
\hline & & Poor & $9(32.1)$ & $19(67.9)$ & & \\
\hline
\end{tabular}

Table 4: Noncompliance rate at more than 2 times among noncompliant to medications $(\mathrm{n}=48)$.

\begin{tabular}{|c|c|c|c|c|}
\hline Various factors & & $\begin{array}{l}\text { >2times missed } \\
\text { medications during the } \\
\text { last } 2 \text { weeks }(\%)\end{array}$ & Odds Ratio & P value \\
\hline \multirow[t]{2}{*}{ Age group } & $\geq 50$ years & $17(58.63)$ & \multirow[t]{2}{*}{3.967} & \multirow[t]{2}{*}{0.0280} \\
\hline & $<50$ years & $5(26.32)$ & & \\
\hline \multirow[t]{2}{*}{ Socio economic status } & Low & $12(54.5)$ & \multirow[t]{2}{*}{1.89} & \multirow[t]{2}{*}{0.2661} \\
\hline & High & $10(38.5)$ & & \\
\hline \multirow[t]{2}{*}{ Residence } & Rural & $11(52.4)$ & \multirow[t]{2}{*}{1.584} & \multirow[t]{2}{*}{0.441} \\
\hline & Urban & $11(40.7)$ & & \\
\hline \multirow[t]{2}{*}{ HT duration } & $<5$ years & $17(53.1)$ & \multirow[t]{2}{*}{2.446} & \multirow[t]{2}{*}{0.1692} \\
\hline & $\geq 5$ years & $5(31.2)$ & & \\
\hline \multirow{2}{*}{$\begin{array}{l}\text { Aware of not to stop } \\
\text { drugs even if BP is } \\
\text { under control }\end{array}$} & Aware & $20(58.82)$ & \multirow[t]{2}{*}{8.571} & \multirow[t]{2}{*}{0.0125} \\
\hline & Not aware & $2(14.29)$ & & \\
\hline
\end{tabular}


Among the noncompliant who missed medications at more than 2 times, significantly higher proportion of hypertensives knew that they should not stop drugs even if blood pressure is under control (58.82\%), when compared to the hypertensives who did not know it (14.29\%), $(\mathrm{p}=0.0125)$, (Table 4).

\section{DISCUSSION}

Noncompliance to medication was a major factor for uncontrolled blood pressure. Drug compliant in this study was $52 \%$ which is lower than a study done in South Africa (63\%), in which the enquiry for drug compliance was 3 days alone, whereas in this study missing of drugs during the past 2 weeks was taken to account. WHO defines drug compliance as consumption of a medication for at least $80 \%$ of the prescribed time. ${ }^{11}$ If hypertensives who missed drugs for 2 or lesser times $(26 \%)$ were considered as drug compliant in this study, then the drug compliant rate becomes $78 \%$, which is almost equal to the previous study done in India (73\%).

\section{Knowledge}

Being a teaching hospital, health education is given on the day of diagnosis of hypertension itself in a separate counseling place by health educators, so among the hypertensives knowledge is more on drug compliance $(81 \%)$ and they had good knowledge about at least any three complications of hypertension $(70 \%)$. In this study about $63 \%$ of hypertensives knew that they had to take hypertensive drugs throughout their life which is in line with South African study (64\%), where $41 \%$ of the participants had the knowledge about cardiovascular complications due to hypertension and almost half of the participants knew about renal, visual and cerebrovascular problems. ${ }^{19}$ In this study most of the participants knew about noncompliance to medication causes cardiac $(72 \%)$, renal $(60 \%)$ and cerebral $(55 \%)$ problems. Very few had knowledge about visual $(28 \%)$ complications.

Practice-In drug compliance, this study result (52\%) was similar with Karachi study (57\%). Noncompliant at more than 2 times of missing drugs were $22 \%$ in this study. This group of hypertensives should be identified and focused to prevent them from developing complications of hypertension. Like this study noncompliance due to forgetfulness (34\%) was more in chapel hill study $(45 \%)$. This indicates that focus and care should be taken over the behavioral aspects in management of hypertension. Disregarding the behavioral aspects in hypertension management leads to harmful and unnecessary escalation of the drug regimen.

Compliance rate according to various factors. In this study compliance rate was not associated significantly with demographic factors and illness factors, which is similar to a study done in Kuwait. This might be due to the symptom free nature of the disease and lack of continuous reminders. This demands for continuous awareness program and reinforcement to improve the compliant status. This study knowledge factor like not stopping drugs even when blood pressure was under control was significantly associated with drug compliance; this is similar with a study done in Saudi Arabia.

Higher proportion of participants who knew about cardiac complication and any 3 complications of hypertension regarding noncompliance were found 3.9 times and 3 times more drug-compliant respectively when compared to the hypertensives that were not aware about it. These significant associations are similar with a study done in South Africa. ${ }^{19}$ This might be due to fear of long term morbidity and mortality due to cardiac problems, which forced them to take drugs regularly.

Significant proportion of participants with good knowledge about any four among five factors pertaining to drug-compliance were found to be 3.1 times more drug-compliant when compared to the hypertensives with poor knowledge. These participants are at low risk of developing complications of hypertension. These factors are comprehensively discussed in this study and were not discussed in any other previous studies.

Noncompliance rate at more than 2 times according to various factors among noncompliant

Drug compliance is consumption of a medication for at least $80 \%$ of the prescribed time. Accordingly, the noncompliant who missed drugs for more than 2 times were at risk of developing more complications of hypertension. Among the noncompliant, older age group hypertensives who missed drugs for more than 2 times were significantly higher $(58.63 \%)$, when compared to their respective counter parts, which is in line with a study published in 2005 .

It was also found that among the noncompliant at more than 2 times of missing medications nearly $59 \%$ had knowledge that they should not stop drugs even if blood pressure is under control. They are in risk of developing all complications of hypertension due to noncompliance. Attitude and behavioral aspect of these individual should be focused to prevent them from the risk of developing complications by improving their compliance rate. This was not discussed in any other previous studies.

Combined health educational approach, behavioral approach and continuous motivation is needed to noncompliant hypertensive males. The present study will provide base line information that will enable to explore the problem at a wide range by conducting more research in larger study populations with different segment of populations and to investigate the problem in a better way and design interventional activities accordingly.

Strength of the study is this study revealed the knowledge and practice on drug compliance among hypertensives 
comprehensively, which were not covered in previous studies. Compliance rate according to various factors were analyzed in this study. Among the noncompliant association of noncompliance rate at more than 2 times of missing of drugs with various factors were studied in detail.

Limitation of the study is this is a hospital based study, so findings could not be generalized to community. This study did not cover attitudes and behavioral aspects of the individuals regarding noncompliance to medications.

\section{CONCLUSION}

About 52\% were taking drugs as prescribed regularly, which shows drug compliance was very poor among males with hypertension. Among the noncompliant, hypertensives aged 50 or more years who missed drugs for more than 2 times were significantly higher and were at risk of developing more complications of hypertension. This study reveals that knowledge factors play a significant role in improving the drug compliance. This study also reveals that noncompliance was also present among participants who had knowledge that they should not stop drugs even if blood pressure is under control.

Recommendations of the study was there is an urgent need for increasing awareness of hypertension and to promote its treatment and control by repeated health education session among the hypertensives. Complex interventions are most effective. Follow several approaches together including, information about hypertension and the need for lifelong treatments, periodic reminders from healthcare system, family support and pharmacy-based programmes. Drugs could be placed at convenient location such as bedside, dining/office table, office bag or with workers boxes.

Combined educational and behavioral approach with continuous motivation increases drug compliance. This requires doctors to orient themselves towards patient's behavior that may interfere with compliance in order to achieve control of hypertension in the community. Health professionals must educate hypertensive patients about their disease, their medications and the consequences of noncompliance with treatment. They need to stress the importance of compliance with their hypertension treatment despite the absence of symptoms which prevent premature deaths, avoid strokes and heart problems. To motivate the defaulters repeated counseling sessions are needed.

Relevance of the study is no previous studies had exhibited various individual factors comprehensively and their association with drug compliance in detail. Previous studies have not focused on proportion of hypertensives who were noncompliant to medications at more than 2 times and less than 2 times individually and their association with socio demographic and knowledge factors. The result of this study is of value to health care providers to understand drug compliance to medications among hypertensives which in turn prevents treatment failures due to noncompliance, prevent premature death and various complications of hypertension. This decreases economic burden to both individuals and to nation.

\section{ACKNOWLEDGEMENT}

Authors would like to thnak Prof. M. K. Sudhahar. M.D., F.C.C.R., Former Professor of Medicine, Sri Ramachandra University, for his suggestions. I also thank to Prof. G.Palani. M.D, B.S.Sc. for his appreciable suggestions, opinions and for permitting me to conduct the pilot study at RHTC, Vayalanallur.

Author's contribution Vanitha D has conceived the idea, designed the methodology and did the data collection, data analysis and report writing. Anitha Rani $M$ has refined the research questions, refined methodology and contributed for data analysis and report writing.

Funding: No funding sources

Conflict of interest: None declared

Ethical approval: The study was approved by the Institutional Ethics Committee

\section{REFERENCES}

1. Lim SS, Vos T, Flaxman AD, Danaei G, Shibuya K, Adair-Rohani $\mathrm{H}$, et al. A comparative risk assessment of burden of disease and injury attributable to 67 risk factors and risk factor clusters in 21 regions, 1990-2010: a systematic analysis for the global burden of disease study, 2010. Lancet. 2012;380(9859):2224-60.

2. Kearney PM, Whelton M, Reynolds K, Muntner P, Whelton PK, He J. Global burden of hypertension: analysis of worldwide data. Lancet. 2005;365:21723.

3. World Health Organization. Global Status Report of NCD 2010. Geneva: World Health Organization, 2011.

4. Walker RW, McLarty DG, Kitange HM, Whiting D, Masuki G, Mtasiwa DM, et al. Stroke mortality in urban and rural tanzania: adult morbidity and mortality project. Lancet. 2000;355:1684-7.

5. Law M, Wald N, Morris J. Lowering blood pressure to prevent myocardial infarction and stroke: a new preventive strategy. Health Technol Assess. 2003;7:1-94.

6. Benner JS, Glynn RJ, Mogun H, Neuman PJ, Weinstein MC, Avorn J. Long-term persistence in use of statin therapy in elderly patients. JAMA. 2002;288(4):455-61.

7. Caro JJ, Salas M, Speckman JL, Raggio G, Jackson JD. Persistence with treatment for hypertensionin actual practice. CMAJ 1999;160(1):31-7.

8. Elzubier AG, Husain AA, Suleiman IA, Hamid ZA. Drug compliance among hypertensive patients in 
Kassala, eastern Sudan. East Mediterr Health J. 2000;6:100-5.

9. Rodgers A, Lawes C, MacMahon S. Reducing the globalburden of blood pressure related cardiovascular disease. J Hypertens. 2000;18 (Suppl. 1):S3-6.

10. Gaziano T, Reddy KS, Paccaud F, Horton S, Chaturvedi V. Cardiovascular disease. In: Disease Control Priorities in Developing World. Jamison DT, eds. Oxford University Press, Oxford, 2006:645-62.

11. Sabate E. Adherence to long term therapies: Evidence for action. Geneva, Switzerland: WHO. 2003;35(3); 121 .

12. WHO. Country Cooperation Strategy Seychelles 2004-2007. Brazzaville: WHO Regional Office for Africa.2005.

13. Campbell NR, Petrella R, Kaczorowski J. Public education on hypertension: a new initiative to improve the prevention, treatment and control of hypertension in Canada. Canadian Journal of Cardiology. 2006;22(7):599-603.

14. Chockalingam A. World hypertension day and global awareness. Can J Cardiol. 2008;24(6):441-4.

15. Stergachis A. IMPACT: improving patients compliance with medication regimens. US Pharmacist. 1998;(Suppl):1-16.

16. Laskar AR, Sharma N, Bhagat N. Lifestyle disease risk factors: a study of awareness and prevalence in North Indian community in Delhi. IJCM. 2010;35(3):426-8.

17. Ambaw AD, Alemie GA, MW S, Mengesha ZB. Adherence to antihypertensive treatment and associated factors among patients on follow up at University of Gondar Hospital, Northwest Ethiopia. BMC Public Health. 2012;12:282.

18. Dennis T, Meera NK, Binny K. Medication adherence and associated barriers in hypertension management in India. CVD Prev Control. 2011;6:913.
19. Akpan Edo T. Factors affecting compliance with antihypertensive drug treatment and required lifestyle modifications among hypertensive patients on Praslin Island. University of South Africa, 2009. Available at http://uir.unisa.ac.za/ bitstream/handle/ 10500/3249/dissertation_edo_t.pdf?sequence=1\&is Allowed=y Accessed 20 March 2016.

20. Subhasis BP, Sarma S. Adherence to antihypertensive treatment and its determinants among urban slum dwellers in Kolkata, India. AsiaPacific J of PH.2011. Available at: http://aph.sagepub.com/content/early/2011/10/12/10 10539511423568.abstract?rss=1. Accessed on 20 March 2016.

21. Almas A, Hameed A, Ahmed B, Islam M. Compliance to antihypertensive therapy. J Coll Physicians Surg Pak. 2006;16(1):23-6.

22. Haruna AJ. Adherence to antihypertensive medication regimens among patients attending the G.P.H.A. Hospital in Takoradi-Ghana, 2006. Available at: http://ir.knust.edu.gh/bitstream/ 123456789/677/1/HARUNA\%20AHMED\%20JAM BEDU.pdf Accessed on 20 March 2016.

23. Rudd P. Clinicians and patients with hypertension: unsettled issues about compliance. Am Heart J. 1995;130:572-9.

24. Al- Mehza AM, Al -Muhailije FA. Drug compliance among hypertensive patients; an area based study. Eur J Gen Med. 2009;6(1):6-10.

25. Khalil SA, Elzubier AG. Drug compliance among hypertensive patients in Tabuk, Saudi Arabia. Journal of Hypertension. 1997;15(5):561-5.

26. Gryglewska B. How can we improve the effectiveness of treatment in elderly hypertensives? Blood Press. 2005;2:46-9.

Cite this article as: Durai V, Muthuthandavan AR. Knowledge and practice on drug compliance among males with hypertension. Int J Community Med Public Health 2016;3:1424-30. 